\title{
PRÁTICA DE ESTÁGIO SUPERVISIONADO: UM CASO DE FORMAÇÃO CONTINUADA DE PROFESSORES
}

\section{SUPERVISED TEACHER PRACTICE: THE CASE OF TEACHER'S CONTINUOUS EDUCATION}

\author{
Lucile Daniel Moreira', Maylta Brandão dos Anjos², Giselle Rôças ${ }^{3}$ \\ ${ }^{1}$ Instituto Federal de Educação Ciência e Tecnologia do Rio de Janeiro - IFRJ - Campus Nilópolis/ \\ Licenciatura em Química/ Bolsista de Iniciação Científica, lucile.ifrj@ yahoo.com.br \\ ${ }^{2}$ Instituto Federal de Educação Ciência e Tecnologia do Rio de Janeiro - IFRJ - Campus Nilópolis/ \\ Programa de Pós-Graduação Stricto Sensu em Ensino de Ciências - PROPEC/ Docente do Mestrado \\ Profissional em Ensino de Ciências, maylta.anjos@ifrj.edu.br; \\ ${ }^{3}$ Instituto Federal de Educação Ciência e Tecnologia do Rio de Janeiro - IFRJ - Campus Nilópolis/ \\ Programa de Pós-Graduação Stricto Sensu em Ensino de Ciências - PROPEC/ Docente do Mestrado \\ Profissional em Ensino de Ciências, giselle.rocas@ifrj.edu.br
}

\section{RESUMO}

A Prática de Estágio Supervisionado é de suma importância para a formação docente e deve ser alicerçada num campo teórico que confira qualidade ao ensino. O estágio funciona como ampla oportunidade de reestruturação e reelaboração do professor, sem contar que ele sofre, além do fenômeno de auto-avaliação, a avaliação de seus pares, no caso em questão orientadores de mestrado que visam avaliar competência, postura, domínio de conteúdo, habilidades e compromisso do mestrando/estagiário. Este artigo busca articular as experiências realizadas em uma Escola Municipal da Baixada Fluminense, sobretudo no que se refere a formação continuada em nível de Pósgraduação dos alunos de um curso de mestrado, tendo como eixo articulador a Prática de Estágio Supervisionado, e como esta contribui para a formação dos mestrandos e, especialmente para a formação dos alunos do ensino fundamental.

Palavras-chave: estágio supervisionado, ensino de ciências, formação continuada.

\begin{abstract}
The importance of teacher's supervised practice should be grounded in a theoretical field, which gives quality education. This practice period serves as an opportunity to restructure and redesign the teacher's methods and conducts in classroom, not to mention that it is a moment to self-evalution as peer evalution in order to assist de the teacher to assess competence, attitude, content domain, skills and commitment of the graduate student / intern. This article seeks to articulate the experiments conducted at the Municipal School of Baixada Fluminense, particularly as regards the level of continuing education in Graduate students of the Master course, with its central theme of Supervised Practice, and how this contributes to the formation of the masters, and especially for the training of elementary school students.
\end{abstract}

Key words: supervised practice, science teaching, continuos education 


\section{INTRODUÇÃO}

De acordo com o parecer CNE/CP 28/2001, do Ministério da Educação, “o estágio curricular supervisionado deverá ser um componente obrigatório da organização curricular das licenciaturas, sendo uma atividade intrinsecamente articulada com a prática e com as atividades de trabalho acadêmico". Portanto, o mesmo se faz necessário não somente para aqueles que cursam licenciatura, mas também para aqueles que retornam à sala de aula na condição de mestrandos e que tem nesse novo perfil a necessidade de se colocarem no processo de reavaliação e análise de seu fazer. Ainda que seja um componente curricular obrigatório, a Prática de Estágio Supervisionado (PES) é de suma importância para o desenvolvimento e capacitação do docente, não somente na sua formação inicial, mas também durante a sua formação continuada, visto que a formação de um profissional não finda ao término de uma disciplina "obrigatória", mas sim se constitui num processo que transcorre na vida acadêmica, pois a abordagem é um meio de valorização da prática docente, alicerçando conhecimentos, não somente teóricos, mas sim em sua práxis.

No caso de um curso de mestrado profissional, a proposta da Prática de Estágio Supervisionado extrapola os elementos de formação/acompanhamento dos mestrandos. Ele atua

[...] como requisito obrigatório para a integralização curricular. É a oportunidade para que o orientador vá à escola, conheça o local de trabalho do orientando e acompanhe a implementação da proposta que gerará o trabalho de conclusão. Em casos de dificuldade de acesso à escola o acompanhamento pode ser registrado por meio de gravações em vídeo ou por outras formas. O objetivo é que o orientador tome conhecimento da realidade da escola ou ambiente de trabalho de seu orientando de modo que, em parceria, possam levantar questões a serem estudadas e assim contribuir efetivamente para a melhoria do ensino no país (DOCUMENTO DA ÁREA 46, CAPES, 2013, p. 24).

Ou seja, é também um momento em que orientadores retornam ao "chão da escola" para que possam acompanhar o desenvolvimento da pesquisa de seus orientandos e, compartilhar experiências com os diferentes sujeitos que vivenciam essa instituição.

A disciplina PES funciona como ampla oportunidade de reestruturação e reelaboração do mestrando. Além de fazê-lo inferir novas questões sobre sua prática, ele sofre, o processo de auto-avaliação, avaliação e percepção no desenvolvimento de suas atividades pelo orientador e demais professores do Programa, bem como de colegas de Edição Especial com os melhores trabalhos apresentados no IV ENECiências: UFF - 13 a 16 de maio de 2014. 


\section{Ensino, Saúde e Ambiente - V 7 (1), Edição Especial, maio de 2014}

trabalho, que visam ajuizar a competência, postura, domínio de conteúdo, habilidades e compromisso do mestrando (MILANESI, 2012). É no fazer docente, que se adquire habilidades e se põe em prática os projetos pedagógicos que vão criar novas oportunidades de análise e de pesquisa. Ao sair de sua zona de conforto e se colocar como um professor que está sendo supervisionado, o mestrando experimenta um retorno à sua formação primeira. Entretanto, nessa experiência se sente mais empoderado, não só do seu saber, mas, sobretudo no domínio do objeto de sua pesquisa e, cumpre assim, o objetivo de um mestrado profissional em Ensino de Ciências, que é de ampliar o horizonte, apresentando caminhos e novas possibilidades do mestrando retomar seu fazer diário como pesquisa e retornar a esse fazer acrescido qualitativamente no que se relaciona às dimensões teóricas, didáticas, pedagógicas e conceituais.

O modelo avaliado foi realizado in loco, a PES faz parte do campo de estudo/trabalho dos alunos de mestrado profissional, uma vez que ele necessita desse ambiente para se tornar um pesquisador de sua prática. Segundo Felício e Oliveira (2008), o estágio supervisionado deve assumir um campo de seriedade que contribua para melhor formação docente. Sendo, também, um meio de aprimorar/problematizar as experiências vividas pelos alunos. Nesse ínterim, a PES pode ser trabalhada conferindo não somente qualidade ao fazer docente, mas também afinando as relações existentes entre instituições de diferentes níveis. Foi o que buscamos fazer ao levar mestrandos à escolas e Secretarias de Educação.

\section{O CASO 1}

O intuito desse artigo foi o de analisar como a disciplina de PES que trabalha firmada num compromisso interinstitucional que busca contribuir para formação continuada de mestrandos do PROPEC.

Dessa forma, a pesquisa foi de cunho qualitativo com livre interpretação das falas e embasadas no trabalho empírico realizado por mestrandos e professores do referido mestrado. Como já dito, a pesquisa se deu através da parceria entre Escolas Municipais da Baixada Fluminense. A condição dos mestrandos já serem professores, os coloca como pesquisadores de sua prática docente e, sobretudo aguça para a formação continuada conferindo maior qualidade de suas aulas aos alunos do ensino fundamental, fato observado a partir dos relatos dos próprios mestrandos e dos Edição Especial com os melhores trabalhos apresentados no IV ENECiências: UFF - 13 a 16 de maio de 2014. 


\section{Ensino, Saúde e Ambiente - V 7 (1), Edição Especial, maio de 2014}

participantes das oficinas, por vezes um público misto, ou ainda, ora só de alunos ora só de professores.

A pesquisa aconteceu por meio de oficinas ministradas pelos mestrandos, os quais desenvolveram atividades em turmas do ensino fundamental abordando temas relacionados diretamente ao Ensino de Ciências. O trabalho realizado por meio da Prática de Estágio Supervisionado foi in loco, onde os mestrandos foram supervisionados pelos seus respectivos professores orientadores do curso de mestrado, pois de acordo com o parecer CNE/CP 28/2001 “o estágio curricular supervisionado é o momento de efetivar, sob a supervisão de um profissional experiente, um processo de ensino-aprendizagem que, tornar-se-á concreto e autônomo quando da profissionalização deste estagiário".

O intercâmbio interinstitucional, já definido por Wendt (2009, p.102) como “intercâmbio de realidades e necessidades, compreendendo o universo do ensino superior e a trajetória da formação no campo de ensino, permitindo inseri-los no universo histórico, sócio, temporal da realidade educacional", foi um dos propósitos da realização da pesquisa. Essa parceria dos programas de pós-graduação Stricto Sensu e das Escolas de Educação Básica não contribui somente para troca de experiências, mas também para uma construção de conhecimentos mútuos, sob outro olhar além do ensino formal em sala de aula, esse conceito de acordo com Tardif (2000) apud Barcelos e Villani (2006, p.94)

[...] torna-se premente o reconhecimento da escola como espaço necessário para o desenvolvimento de uma cultura profissional baseada no intercâmbio de experiências e na reflexão compartilhada entre universidade e escola, porque os saberes profissionais, que englobam conhecimentos, competências, habilidades e atitudes são mobilizados, construídos e incorporados somente na prática.

Diante dessa parceria, verificamos por meio da fala dos mestrandos ${ }^{1}$, a importância desse intercâmbio, e como este alimenta os saberes e proporciona uma reflexão acerca do projeto pedagógico. É através da fala desses mestrandos, que se encontram num momento de reflexão da sua própria prática pedagógica, que podemos confirmar a necessidade da parceria entre instituições de ensino superior e escolas de educação básica. Os relatos abaixo transcritos refletem essa necessidade:

\footnotetext{
${ }^{1}$ Os relatos estão disponíveis no Youtube. Todos os participantes assinaram termo de uso da imagem e da voz, bem como do conteúdo para analyses e divulgações acadêmicas.

Edição Especial com os melhores trabalhos apresentados no IV ENECiências: UFF - 13 a 16 de maio de 2014.

ISSN 1983-7011
} 


\section{Ensino, Saúde e Ambiente - V 7 (1), Edição Especial, maio de 2014}

"Na minha opinião todo intercâmbio é muito válido para ambos os lados: para nós do mestrado, como campo de experimentação, coleta de dados, teste da realidade... Pra escola também é muito interessante pela ação de novas práticas, observação de outros modos de fazer" (sujeito 9).

"Eu acredito que esse intercâmbio possa contribuir tanto para a escola quanto para o mestrado, oferecendo experiência aos alunos de atuar de repente numa esfera que não seja de atuação deles e levando aos alunos dessa escola, conceitos, ideias, aprendizagens que eles iriam vivenciar na escola em si" (Sujeito 7).

"Eu acho esse intercâmbio muito positivo, a escola ganha e o Instituto ganha mais ainda. É importante a gente saber novas realidades, os colegas que não têm esse acesso às escolas públicas, terem esse acesso. Apesar de ser um dia só, mas eu achei importante. Eu acredito que seja de grande benefício para ambos, tanto para a escola quanto para os alunos" (Sujeito 8).

"Eu acho que deveria ocorrer mais, porque é um trabalho muito bom, numa comunidade que precisa. Muitas pessoas não sabem que têm o Instituto aqui no bairro e quando a gente leva, leva para dentro dessas escolas, mostrando o trabalho, mostrando para outros professores que é possível continuar estudando, acho que deveria acontecer mais esse tipo de intercâmbio" (Sujeito 5).

Wendt (2009) enfatiza a importância do papel do estágio na escola, pois

$\mathrm{Na}$ formação do professor, os estágios são um instrumento de intercâmbio de realidades e necessidades, compreendendo o universo do ensino superior e a trajetória da formação no campo de ensino, permitindo inseri-los no universo histórico, sócio, temporal da realidade educacional (WENDT, 2009, p. 102),

As contribuições educacionais e epistemológicas que a Prática de Estágio Supervisionado levam à escola se faz presente quando o mestrando vê além do imaginário dos estudantes, levando para eles um mundo de opções. Porém, ele não pode ser "apenas um espectador da realidade escolar", mas um protagonista que observa, pratica e faça disto uma vivência no universo escolar (WENDT, 2009). Ainda que, em determinadas situações, os estagiários (nesse caso, assumimos que são os mestrandos) mais críticos e comprometidos são vistos como pessoas indesejadas dentro das escolas, como enfatiza Barcelos e Villani (2006), sendo considerados seres estranhos "invadindo" um espaço que não lhes pertence, "retirando" a pouca carga horária que o professor possui para ministrar sua aula. A afirmativa dos autores é reforçada pelo relato de um dos mestrandos que participaram da experiência ao destacar que,

“[...] eu acho importante a universidade aparecer na escola, ela participar da escola, mas que fosse de uma forma mais contínua, de uma forma mais sistemática, porque [...] eu sinto que a gente está invadindo um espaço que não é nosso, e a escola se posiciona de uma forma mais refratária [...]" (sujeito 10).

Apesar de ser uma realidade recorrente, é nessa vivência que o mestrando 


\section{Ensino, Saúde e Ambiente - V 7 (1), Edição Especial, maio de 2014}

precisa atuar como um ser crítico e reflexivo, sendo necessário destacar que a presença dele poderá contribuir de forma significativa para a aprendizagem dos alunos. Os professores que, eventualmente, se demonstram incomodados, precisam ser convidados a discutir e compreender a importância do papel do estagiário/mestrando nas escolas (WENDT, 2009). Deve-se considerar também que os acordos precisam envolver esses sujeitos, pois em geral, a direção assume os compromissos, e são os professores que necessitam adequar em sua carga horária as atividades propostas, e por vezes, não previamente discutidas com eles. Conforme ressaltado pelo sujeito 10, as atividades precisam ser mais perenes. Avaliações e reflexões sobre as experiências já realizadas precisam ser postas em prática, com o intuito de concluir o que se pretende nessa ação interinstitucional. O que vemos é apenas o começo de uma intenção que é válida e deve ser constante.

As atividades realizadas pelos mestrandos na escola não se deu de forma contínua, está aí uma das críticas que assumimos na pesquisa. Entretanto na fala dos professores supervisores pudemos corroborar para a inserção do lúdico, colaborando para a pesquisa de formação dos professores

“A educação pública é muito carente de atividades como esta que nós apresentamos aqui hoje, em função disso, o rebuliço que a gente causa na turma, mas pelo andamento da aula nós observamos que um ensinamento aconteceu. Muitos alunos conseguiram absorver alguns conceitos que estavam sendo passados" (Sujeito 3).

“[...] os conteúdos que foram tratados os alunos vêem no ensino fundamental [...] o ensino de ciências vem progredindo ao longo dos anos, então desde da primeira série do ensino fundamental essas questões de ciências vão sendo colocadas e você vai aumentando o grau de complexidade ao longo dos anos" (Sujeito 2).

Os mestrandos, através de sua formação continuada, saindo de sua zona de conforto, levaram aos alunos do ensino fundamental um pouco de conhecimento sobre o que é fazer ciência e quais eram os propósitos do ensino de ciências. Verificaram que foi gratificante esta troca de oportunidades, conforme observamos abaixo:

"Achei muito interessante, até porque aproximou o conteúdo daqueles alunos, que provavelmente não teriam contato com a disciplina, agora, nessa série e na faixa etária que se encontram" (Sujeito 7).

"Eu fiquei surpreso com o resultado, eles prestaram muita atenção, participaram fazendo pergunta, mostraram bastante interesse, que à princípio eu achei que não seria tanto. A turma superou a minha expectativa" (Sujeito 12). 


\section{Ensino, Saúde e Ambiente - V 7 (1), Edição Especial, maio de 2014}

"Eu achei que foi melhor até do que eu esperava por ser uma turma de sétimo ano, eu achei que ia ser uma tarefa difícil por eles não associarem muito com a química, já que eles não trabalham esse tema em sala, mas a gente começou a debater de uma forma mais generalizada de ciências, então o trabalho se desenvolveu bem [...]. Muitos conseguiram construir ali algumas ideias legais" (Sujeito 13).

Ainda que alguns alunos-professores tenham relatado que a atividade deveria ser de forma contínua, eles salientaram

"Acho interessante, eu acho importante, mas tem que ser um trabalho contínuo. Qualquer tema que aproxime o aluno da ciência, ele já é muito interessante, qualquer atividade que estimule o interesse do aluno já é muito interessante, então, eu acho que foi um dos temas que cumpriram esse papel" (Sujeito 12).

A PES deve assumir um compromisso que tenha não somente a continuidade como foco, mas também a formação continuada numa ação interinstitucional. Dessa forma, tanto para mestrandos e professores deve ser um momento de inteira ação pedagógica, em que esteja no palco a organização, o método, o conteúdo e a didática. Ao oferecer oficinas, palestras e seminários, avaliamos que a ação educacional do mestrando não foi vista somente como a prática de um docente, mas também como pesquisador, que se colocando na condição de pesquisado retorna ao seu campo de ação acrescido da crítica propositada e sólida para a melhoria de seu trabalho. Assim, os temas dos encontros versaram de forma prática como se constitui o Ensino de Ciências, a exemplo trazemos a seguinte fala

“[...] Um tema bastante interessante que é o papel da ficção científica no desenvolvimento do conhecimento científico, da simpatia pela ciência, pelo gosto da ciência, das impressões que ficam [...], porque a gente sabe que neste mundo, sobretudo as grandes mídias é muito perversa com o ensino de ciências [...] as histórias em quadrinhos, sobretudo, no trato da ficção científica, acabam contribuindo, muitas vezes, negativamente para isso. Âs vezes não, às vezes positivamente que desperta até algumas paixões" (Sujeito 1).

\section{CONSIDERAÇÕES FINAIS}

Há muito que se fazer e debater. Novos modelos e estratégias estão constantemente sendo testados. Acordos e calendários prévios estabelecidos entre as instituições foram e são atropelados por ações externas: greves, eventos de grande porte (os quais os órgão que governam não hesitam em penalizar a escola com a suspensão de aula), recessos decretados a posteriori, ou mesmo questões pessoais (doença ou outros motivos). Além das questões de logística, há que se planejar e acompanhar o que os 


\section{Ensino, Saúde e Ambiente - V 7 (1), Edição Especial, maio de 2014}

mestrandos apresentarão, sendo esse papel essencial dos orientadores, e o ideal, que fosse em comum acordo com os professores que os receberão em suas salas de aula.

O mestrando ao experimentar essa atividade de PES formula suas críticas, se auto-avalia e é avaliado. O olhar dele fica aguçado e comprometido ficando ainda mais atento aos sinais que redundarão numa prática mais afinada com a qualidade do seu falar, fazer, construir e consolidar no outro e em si o prazer das descobertas, das hipóteses e de um conhecer que o torna sujeito libertado de antigas cegueiras e opressões e libertador do outro.

Embora muitos avaliem que a Prática de Estágio Supervisionado seja mais um protocolo do currículo a ser cumprido, observamos que há diferentes formas de executálo. Optamos pela premissa de que ele possa fazer a diferença, ainda que envolva um esforço maior de organização. Optamos por um formato que consolidasse além da ação interinstitucional, uma parceria de formação continuada entre mestrando/pesquisador e orientador/pesquisador tão necessária e vital num mestrado profissional de Ensino de Ciências. É nessa lógica e nesse interesse que a PES tem buscado o seu funcionamento, sua funcionalidade e seu desenvolvimento. Portanto,

“[...] o ensino de ciências vem progredindo ao longo dos anos, então desde da primeira série do ensino fundamental essas questões de ciências vão sendo colocadas e você vai aumentando o grau de complexidade ao longo dos anos" (Sujeito 2).

Após cinco anos de existência do Programa, observamos que a colheita não é pontual. É processual, contínua e feita de sucessivas experiências que amadurecem o pensar, especifica o olhar, refaz, reconduz e reconstrói. Por isso, a experiência continuada aguça e confere qualidade ao ensino.

Cabe registrar que para além dos propósitos da disciplina PES em si, ao mudarmos de ambiente e trabalharmos em escolas do ensino fundamental, proporcionamos uma interlocução que dinamiza a escola, oferecendo aos envolvidos um momento diferenciado, uma oxigenação no seu processo escolar. Um envolvimento outro que faz com que professores e alunos se sintam percebidos, importantes e alvo de uma atuação que extrapola os limites da escola, trazendo outros profissionais com novas abordagens e conteúdos do Ensino de Ciências. Esse profissional para sua boa consecução deve se valer de várias práticas, linguagens e abordagens que apresente coerência, razão e significado a qualquer conceito científico. Nessa lógica um dos 
professores supervisores extrapola a sua prática e reflete que algo mais precisa ser realizado. Amplia suas percepções ao afirmar que

"[...] o processo de Iniciação Científica e a divulgação da ciência para formar cientistas que é o que o país quer fazer com projetos como Ciências sem Fronteiras, etc, precisa ser iniciado no ensino fundamental. $\mathrm{O}$ ensino fundamental precisa ser $\mathrm{O}$ foco das ações de formação em ciência, [...] no ensino médio é importante, tem um papel importante, mas o sujeito no ensino médio já chega com os pré-conceitos formados a respeito de ciências e das suas grandes áreas: química, física e biologia, todos os estereótipos. [...] Essa experiência foi extremamente interessante, eu vejo como muito mais rica em termo de formação de ciências do que em turmas de ensino médio" (Sujeito 4).

Partilhamos, assim, essa ação por avaliar que a comunicação e a troca de experiência são capazes de ressignificar antigas práticas e disciplinas dando novo vigor que reacende o que antes parecia amorfo e sem vida.

Salientamos, ainda, que nessa disciplina produzimos dois documentários, síntese de todas as oficinas oferecidas nas escolas, intitulados "Estratégias de Ensino I e II" que encontram-se disponíveis no YouTube e no site institucional do IFRJ. Avaliamos que assim, além do registro de um trabalho, estamos democratizando um saber produzido que tem no seu objetivo conferir maior divulgação e qualidade ao Ensino de Ciências.

\section{REFERÊNCIAS}

BARCELOS, N. N. S.; VILLANI, A. Troca entre universidade e escola na Formação docente: uma experiência de Formação inicial e continuada. Ciência e Cognição, v.12, n.1, p.73-97, 2006.

BRASIL. Documento de área 2013 - Área 46: Ensino. Coordenação de Aperfeiçoamento de Pessoal de Nível Superior (CAPES). Disponível em<http://www.capes.gov.br/images/stories/download/avaliacaotrienal/Docs_de_area/E nsino_doc_area_e_comissão_block.pdf > acessado em 10 de janeiro de 2014.

BRASIL. Ministério da educação. Conselho Nacional de Educação. Parecer no 28, de 02/10/2001. Disponível em< http://portal.mec.gov.br/cne/arquivos/pdf/028.pdf > acessado em 10 de janeiro de 2014. FELÍCIO, H. M. S; OLIVEIRA, R. A. A Formação prática de Professores no Estágio Curricular. Educar em Revista, Curitiba, n.32, p. 215-232, 2008.

MILANESI, I. Estágio Supervisionado: Concepções e Práticas em Ambientes Escolares. Educar em Revista, Curitiba, Brasil, n.46, p.209-227, 2012.

WENDT, D. C. A prática do estágio supervisionado e a escola - um desafio. Eletras, v.18, n.18, p. 102-111, 2009. 